\title{
Method Engineering: Current research directions and implications for future research
}

\author{
Juha-Pekka Tolvanen, Matti Rossi and Hui Liu \\ Department of Computer Science and Information Systems \\ University of Jyväskylä \\ P.O. Box. 35, 40351 Jyväskylä, Finland \\ E-mail: \{jpt,mor,huiliu\}@hyeena.jyu.fi
}

\begin{abstract}
In this study we investigate method engineering research by classifying studies into three contexts: technology, language and organization. Within each context we examine research bias, research outcomes and use of alternative research methods. This survey reveals the inherent bias of ME research towards tool and language development at the cost of empirical studies. We lack investigations of why organizations develop their own "variants" of system development methods, and how they manage their method engineering efforts. These observations lead us to suggest some directions for future research, which relate both to actual research questions and to the use of complementary research methods.
\end{abstract}

\section{Keywords}

Metamodeling, method engineering, system development methods, research methods

\section{INTRODUCTION}

From time to time every research domain should take a closer look at what kind of research efforts have been carried out, what have been the results so far, and where research is currently heading. This kind of survey reveals what kinds of research questions are emphasized, and more importantly, what questions are being ignored, and what research methods are used or should be used.

The starting point for this study is the obvious need to make a survey of past research in method engineering (ME). By ME we mean a discipline of designing, constructing and adopting methods and tools for information systems development (Kumar and Welke 1992, Brinkkemper 1995). The area of ME has grown from two observations: First there has been a need to describe different information system development (ISD) approaches by a common language in order to compare them (e.g. Olle et al. 1983). Second, there has been a need to 
develop support environments for methods (Kottemann and Konsynski 1984, Bubenko 1988). When the development of a CASE tool for a given method was observed to be too expensive, the idea of generic CASE environments, or CASE toolkits, emerged (Kottemann and Konsynski 1984, Kumar and Welke 1992).

The need of an investigation into ME research is motivated by some observations. First, there exists a relatively large body of research on ME for the basis of the survey. For example, significant research effort has recently been expended on developing new, or extending available languages for method modeling (e.g. Smolander 1991, Hofstede 1993, etc.). Another example is the emergence of several metaCASE tools (e.g. Sorenson et al. 1988, Smolander et al. 1991, Heym and Österle 1993 etc.). Second, research on ME has gathered growing interest during this decade, and this trend will most likely continue. Consequently, we face the need to solicit research questions that have remained unanswered, and to develop research methods that can improve the research being done. Finally, a survey to ME literature is important simply because such studies have not been made.

As the title of the paper indicates, the objective of the study is twofold. First, we will analyze what aspects and questions of ME have been studied, how they have been studied (i.e. which research methods have been applied), and what have been the most remarkable findings. The survey is conducted by analyzing ME literature within three different contexts: technology, language and organization context. Each context is also analyzed by the use of research methods. The results of the study clearly show a bias in current ME research, both related to the contexts (i.e. technology and language), and applied research (i.e. language construction and tool development) and basic research (i.e. theory building for ME). The second objective of our survey is to propose research topics that have remained unanswered. Similarly, we should examine the weaknesses in the use of various research methods and propose research approaches for future research on ME. We hope that the study will provide insights into current research directions in ME research as well as highlight areas in need of future research.

The paper is organized as follows. In the next section we shall discuss the foundations of $\mathrm{ME}$ and describe the framework used in analyzing ME research. Section 3 presents the survey, and Section 4 focuses on the use of research methods. Section 5 proposes future research directions and topics. Finally, Section 6 summarizes the study.

\section{METHOD ENGINEERING: A DEFINITION AND A FRAMEWORK FOR THE STUDY}

\subsection{Foundation and definition}

In its simplest form we can say that a metamodel is a conceptual model of a development method (Brinkkemper 1990). Consequently, metamodeling can be defined as a modeling process, which takes place one level of abstraction and logic higher than the standard modeling process (Gigch 1991). A metamodel captures information about the concepts, representation forms (or signs, cf. Leppänen 1994), and uses of a method. For example, in data-flow diagrams the concepts used to model systems are processes, data stores, external entities and various relationships between them. Moreover, the metamodel of data flow 
analysis defines how each object (concept) is represented (e.g. the symbol definition for an external entity is a square), and in what order the system model should be created (e.g. topdown structure). The relationships between modeling and metamodeling are illustrated in Figure 1 (cf. Brinkkemper 1990).

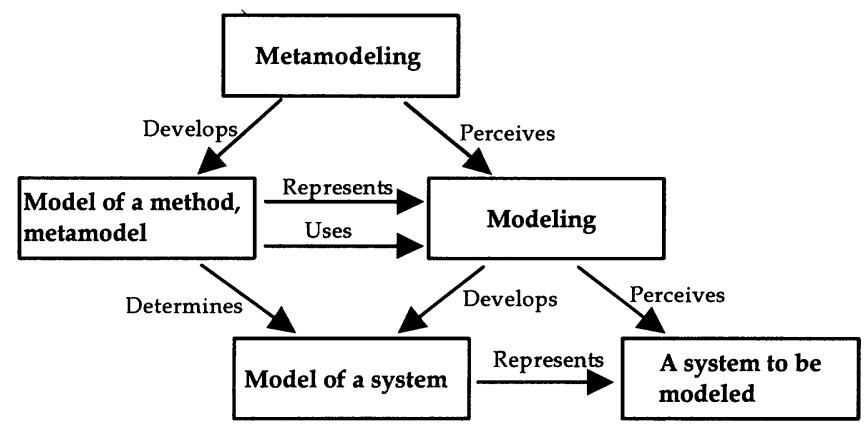

Figure 1. Metamodeling and modeling.

Configurable CASE tools, or CASE shells (Bubenko 1988), or metasystems (Sorenson et al. 1988) use a set of primitives, which allow them to describe a given method quickly and mechanisms to implement a tool to support the defined method. The first configurable CASE environments used complicated textual languages for method definition (e.g. see ISDOS 1985). It soon became evident that "Design of methodologies and applications systems are very comparable exercises in human endeavor. In both cases one has to decide what data is needed and what processes are to be supported. This recursivity (if that's the right word) means that one should be able to specify a design methodology in itself - an assertion that was made in earlier days about programming languages" (Olle et al. 1983 p.8). This recursivity led to the foundation of the area of method engineering (Kumar and Welke 1992).

Brinkkemper (1995) has defined method engineering as "a discipline to design, construct and adapt methods, techniques and tools for the development of information systems". If the method engineering process is supported by specific computer aided tools we call the engineering discipline Computer Aided Method Engineering (CAME), and the supporting tools CAME tools. A person responsible for developing and implementing method specifications is called a method engineer.

\subsection{A taxonomy for ME research}

Throughout this paper we shall apply a framework in surveying and analyzing ME research. The framework consist of two dimensions: the contexts of $\mathrm{ME}$ and research methods. The context dimension includes a technology context, a language context and an organization context (Lyytinen 1987), and they are used to classify the literature on ME. The technology context refers to various tools needed for processing, storing and retrieving descriptions of both ISD methods and system models. Thus, the technology provides a platform and 
supporting mechanisms for ME. The language context refers to the method modeling languages applied in ME. The languages are used for example in describing conceptual structures, representations and use situations of methods. Finally, the organization context connects method engineering with its purpose, goals, supporting organizational structures and mechanisms.

Although some other frameworks could also suit our survey, we believe that the three contexts selected are general and exhaustive enough to classify ME into distinct domains. For example the three contexts cover the domains of ME proposed by Kumar and Welke (1992), Heym and Österle (1993), Brinkkemper (1990), and Wijers (1991).

\subsection{The use of research methods}

The second dimension of the framework consists of research methods and allows us to examine the research in each context. The classification into research methods is important since ME is a relatively new research field in which complementary research efforts are needed to improve the quality of the research outcomes. In using this dimension of the framework we shall investigate the current use and the possible bias of research method use (Section 4), and later recommend topics for future research (Section 5).

The selected taxonomy of research methods includes the following types: survey, field study, laboratory experiment, case study, action research, applied, basic and normative. In principle other taxonomies could be applied but the selected one has been proven suitable for surveying similar research fields, such as CASE (Wynekoop \& Conger 1991) and ISD methods (Wynekoop \& Russo 1993). Each research method is briefly described below. A more thorough discussion of characteristics, strengths and weaknesses of different research methods can be found in Wynekoop and Conger 1991, Galliers 1991, Benbasat et al. 1987, Jenkins 1985, and WoodHarper 1985.

The first five research methods are empirical ones based on observation or interpretation. Survey is based on gathering field data using sampling and typically questionnaires and interviews. The data gathered focuses on a snapshot of practice, and independent variables are not manipulated. Field study focuses on evaluating changes in selected organizational systems. Here dependent variables are systematically measured, but not manipulated. Laboratory experiments allow researchers to create settings in which precise relationships between variables can be controlled and measured. By replicating experiments with multiple samples generalizations can be obtained that are valid outside the sample population. Case studies are evaluations of particular subjects, such as an organization, a group of people, or systems, at a point of time. They attempt to capture the "reality" in greater detail than any of the above research methods; typically no control of the phenomena is exercised. Action research can be understood as a case study with the exception that the researcher, using qualitative and "typical" representatives from the sample, participates in the area of study and simultaneously evaluates its results. Thus, in action research there is a possibility to obtain a deeper and first-hand understanding of the situation.

The last three research methods, i.e. applied, basic and normative, are based on researchers' ideas as well as on comparing them with other perspectives or ideas. Applied research can be characterized as goal-directed: a specific goal is known and the usefulness of the developed or designed outcome can be evaluated and compared to similar ones. Basic research deals with developing new theories based on the expertise and reasoning capabilities of the researcher. 
Normative writing include attempts to concept development, presentation of ideas and applications, or ISD method descriptions. This paper clearly belongs to the normative category.

\section{SURVEY INTO ME RESEARCH}

In this section we shall apply the proposed framework to survey the literature of ME. Basically we tried to collect a representative set of papers for each category and, if possible, papers that also address the use of various research methods. For each context the following features are discussed: description of the context from the ME viewpoint, description of the research done, results of the research efforts, and questions that have been left unanswered.

\subsection{Technology context}

Lyytinen (1987) uses the term technology context to refer to "the view of how to efficiently process and store signs (data) in some material carrier". In ME this can be interpreted as a viewpoint of what kind of technical tool environments are used during method development, and how effectively ISD method representations can be transformed into CASE environment representations (Karrer and Scacchi 1993).

One major research stream in ME has traditionally focused on the development of tools for capturing method knowledge (cf. Heym and Österle 1993, Harmsen et al. 1994a, Verhoef et al. 1991), as well as on building generic CASE toolkits which can be customized for different methods (cf. Teichroew et al. 1980, Chen et al. 1989, Sorenson et al. 1988, Bergsten et al. 1989, Smolander et al. 1991, Rossi 1995, Grundy and Venable 1995).

The technology contexts can be further divided into two broad categories by how they model the object systems (Lyytinen 1987). These categories are data oriented and process oriented approaches. In ME a similar division can also be observed: there is a class of metalanguages and meta systems that model the data models of methods and support the storage of models made according to these definitions (Sorenson et al. 1988, Smolander 1991, etc.). In the process camp - with fewer representatives than data oriented — the research has focused on process representations and tools which support the enactment of these processes (Hofstede, et al. 1993, Wijers 1991, Hidding et al. 1993, etc.).

As in CASE research (cf. Wynekoop and Conger 1991) there is a bias towards building metaCASE and CAME environments rather than evaluating them. There are many articles that describe either principles and requirements for such environments (cf. Marttiin et al. 1995, Harmsen and Brinkkemper 1993, Goldkuhl and Cronholm 1993, Heym and Österle 1993), or represent how one particular metasystem has been implemented and how it works (cf. Teichroew et al. 1980, Sorenson et al. 1988, Bergsten et al. 1989, Chen et al. 1989, Smolander et al. 1991, Rossi 1995, Jarke et al. 1991). A number of articles describe individual aspects of metaenvironments for different purposes. See for example transformations (cf. Boloix et al. 1991a), metrics (cf. Boloix et al. 1991b), automatic diagram generation (cf. Protsko et al. 1989).

There is, however, a paucity of research that describes the use of these tools in practice. Only two empirical studies addressing the capabilities of adaptable environments were found: Cronholm and Goldkuhl (1992) studied method adaptations done with four different tools and 
five methods. Marttiin et al. (1993) made laboratory experiments by adapting the same method for three different CASE shells. These studies reveal that CAME tool developers have concentrated so far on techniques that allow tool customization and method adaptation rather than on developing techniques and principles for utilizing tool based knowledge about methods, for example in method selection, method composition, construction, and reuse. Hence, without proven ME principles on method construction and experience, the development of tool support for ME will be slowed down, and thus will remain in its infancy.

\subsection{Language context}

An IS language provides a means and an environment for linguistic communication which encompasses the use, nature, content, context and form of signs included in the IS (Lyytinen 1987). Seen in this light, the ME language context covers the language facilities for method construction, use and evaluation. The current research on ME languages has mainly focused on the following issues: (1) the metamodeling formalisms for data (i.e. product)-oriented models, process-oriented models of methods, or both; (2) mechanisms for integrating methods; (3) evaluation of the ISD methods; and (4) the effective representational paradigms of ME languages. Note that rather than being orthogonal to one another, these issues are internally related. Below we shall examine each category and summarize main topics of the research.

\section{Metamodeling formalisms}

The research in metamodeling formalisms has been so far one of the most intensively studied areas in ME. This is rational as it forms the basis for systematic ME. The general requirements for ME language can be found: Kottemann and Konsynski (1984), Marttiin et al. (1995), and Welke (1992) recognize the need of rich semantic constructs for modeling the conceptual structure and constraints of methods. Rolland et al. (1995) present a set of characteristics of process models which a meta-process model should cope with.

Starting from Teichroew et al. (1980), most of the meta-data modeling formalisms rely on an existing semantic model (Hull and King 1987). Two types of semantic models, ER-based models and NIAM-based models have been investigated in particular. Extensions to the ER model (Sorenson et al. 1988, Welke 1992, Smolander 1991) seek to improve the expressive power by directly enforcing certain integrity constraints (Welke 1992, Kelly and Tahvanainen 1994), or by representing complex objects (Welke 1992). The developed NIAM-based conceptual metamodeling formalisms (Bommel et al. 1991, Hofstede, et al. 1993, Hofstede and Weide 1993a) attain similar goals, but are founded on a more formal basis than the ERbased ones. The higher level degree of formality have made it easy to develop conceptual manipulation languages, like Lisa-D (Hofstede et al. 1993), to manage model (schema) evolution (Proper and Weide 1994), or to unify the object-role models (Bronts et al. 1995). For other metamodeling formalisms, Saeki and Wenyin (1994) have adapted an objectoriented modeling language called Object-Z. Ahituv (1987) introduces a formal metamodel, which views an information system as the data flow that moves from one state to another, and by which some existing methods can be modeled. The work of (Oei et al. 1992, Oei and Falkenberg 1994, Oei 1995) introduces a formal language for modeling methods and transforming them into a method hierarchy. The functionality of a method engineering 
language called MEL is sketched by Harmsen et al. (1994a) and Brinkkemper (1995). MEL is a specification and manipulation language for situational method construction.

Another aspect of ME, meta-process modeling, is less developed than the data aspect*. Nevertheless, the research can be classified into three categories of process modeling (Dowson 1987): activity-oriented, product-oriented, and decision-oriented. The formal model called "task structure" (Wijers 1991, Hofstede and Nieuwland 1993) has been developed to specify the relationships among the modeling tasks targeted to achieve certain objectives. The meta-process model of Tolvanen et al. (1993a) is able to specify activity models and agent models which specify, respectively, activities performed and the agents involved in utilizing a method. These two meta-process models are activity-oriented. The meta-process model proposed by Marttiin (1994) supports essentially both the specification of modeling products and the activities needed to make it evolve. It is, therefore, a product oriented model. The proposal of Rolland et al. (1995) focuses on the specification of successive transformations of the modeling product looked upon as consequences of decisions. Thus, this model falls in the last category. The strategies of integrating a meta-data model and a meta-process model are also addressed by Wijers and Dort (1990) and Tolvanen et al. (1993a).

\section{Integration of methods}

Integration of methods here refers to the capability of a ME language to associate multiple meta (data) models and to administrate, to cross-check, to reuse, to transform, or to compare them. To provide a comprehensive administrative functionality, the already mentioned modeling language MEL includes a set of operations for specifying, updating, selecting and assembling method fragments (Harmsen et al. 1994a). Kelly and Tahvanainen (1994a) introduce an approach based on the mechanisms of "property sharing" and type reuse to integrate methods that are used in parallel to model the same real-world domain. Motivated by the same goal, the proposal of Saeki and Wenyin (1994) associates interrelated semantic constructs (data types) to the same object (instances) domain. For reuse, two recent studies have suggested a framework for organizing "reusable" method fragments (Rossi and Tolvanen 1995, Brinkkemper 1995).

An approach for transforming specifications between different methods is reported in Boloix et al. (1991). Another approach for integrating methods, which is particularly wellsuited for method comparison, is the aforementioned work of (Oei et al. 1992, Oei and Falkenberg 1994, Oei 1995). One of its distinct features is its rationale of harmonizing metamodels by transforming them into a common metamodel hierarchy (MMH) following certain criteria, thus providing a platform for comparing them.

\section{Evaluation of methods}

One driving force for ME is the need for a systematic and objective means ${ }^{\dagger}$ to compare or evaluate methods, with the aim of reducing the "YAMA (Yet Another Modeling Approach) Syndrome" (Oei et al. 1992) or "chopping down the methodology jungle." (Hofstede and Weide 1993b). Two types of research can be distinguished according to the aim of method

\footnotetext{
* Although numerous process models have been proposed for software engineering, some of which can be used in principle as meta-process models, we restrict our attention here to those process models explicitly developed for ME.

† We therefore focus on the formal systematic approaches for method evalution, excluding the numerous studies using an ad hoc means for method comparison.
} 
evaluation. One stream attempts to find prominent characteristics of methods by comparing a set of methods based on their meta-data model or meta-process model, or both (Hong et al. 1993, Song and Osterweil 1992, Song and Osterweil 1994, Oei 1995). These characteristics include similarities and differences among a set of methods (Hong et al. 1993, Song and Osterweil 1992), or even expressiveness, liability or generality (Oei 1995). Another type is aimed at analyzing the complexity-based features of methods based on a standardized method metrics standard, as proposed by Rossi and Brinkkemper (1995). An obvious benefit of this approach over the former is that it could easily be automated because of its formal and strict mathematical basis.

\section{Representational paradigms of ME languages}

Overall, metamodeling languages need a variety of representation forms. Research has shifted from the early textual style expressions as adopted in Teichroew et al. (1980) and Wijers (1991) to two-dimensional visual languages. The development of visual metamodeling languages has been heavily focused on diagrammatic paradigms, motivated by the fact that a large amount of methods are developed with diagrammatic representations. Hofstede and Weide (1993b) emphasize the importance of diagrammatic formalization in instantiating a method, and develop a general approach for such formalization. Sommerville et al. (1987), Smolander et al. (1991), Protsko et al. (1989), and Hofstede et al. (1992a) have proposed languages to represent graphical notations of a method, their connections, and/or graphical constraints. In addition, Kelly (1994) and Kinnunen et al. (1994) investigate the utilization of a matrix format as a visual representation form for metamodeling. A recent trend extends these developments to several representational paradigms, establishing a multiparadigmatic representational metamodeling environment. As an example, the MetaEdit + metaCASE environment supports modeling of a method using a diagram, a matrix (Kelly 1994), or a table, and also a diagrammatic mode of querying method repository information (Liu 1995).

\subsection{Organization context}

The organization context is essential for ME because the development and use of ISD methods always involves organizational structures, processes and interactions between people. Within the organization context methods can be seen as organizational knowledge of ISD, which evolves and needs to be managed. Similarly, because ME is essentially the same kind of process as ISD it involves human interactions, such as decision making on method selection and assembly, training on methods, operative control on method use, collecting and sharing experience of method applicability.

Within the organization context several survey based studies (e.g. Wijers and Dort 1990, Aaen et al. 1992, Yourdon 1992, Russo et al. 1995) have revealed that ISD methods are developed or adapted locally. For example, a survey of over 100 organizations' use of ISD methods (Russo et al. 1995) shows that more than $2 / 3$ of the companies have developed or adapted their methods in-house. Also, $89 \%$ of respondents believed that methods should be adapted on a project-by-project basis.

Although the surveys clearly reveal that local method engineering take place in practice they do not explain in more detail why and how local methods are produced and how the ME efforts are organized. If organizations make their own versions of methods, these issues must somehow be managed within the organizations, and this too could be studied empirically. The 
only research available on these issues consists of two field studies: Smolander et al. (1990) examined the adaptation of tools and methods in eight companies, and Cronholm and Goldkuhl (1993) studied five CASE tool adaptation projects. One of the main results of these studies showed the absence of general strategies in ME. In adaptation projects several factors, such as the size and skills of the organization as well as technology, can shape ME strategies. No systematic methods or use of metamodeling languages was encountered. Although these studies identify key organizational requirements (e.g. related to issues on management and user support, and on sufficient method knowledge) and problems (e.g. time and resources needed) related to ME they are still tool-focused. For example, most of the adaptation problems are related to the technical features and capabilities of the tools, rather than to organizational issues. Similarly, Bubenko (1988) inspected the situational factors that affect the choice of metaCASE technology: from the viewpoint of organizational context the factors claimed to favor metaCASE are experience of using a particular method, support for in-house methods, and better acceptance of the adapted tools.

Some studies have also reported experiences of ME (cf. WoodHarper 1985, Aalto 1993, van Slooten 1995, Tolvanen 1995, Vlasblom et al. 1995). They still tend to focus on describing developed methods and tools, rather than arguing for or against organizational support. Based on the experiences of ME efforts some studies have proposed frameworks (Slooten and Brinkkemper 1993, Tolvanen 1995), or metamodeling guidelines (Tagg 1990, Tolvanen and Lyytinen 1993b) for ME. These either follow a fairly narrow view of organizational support (e.g. the only unit is a ME/ISD project), or are limited to specific tasks of ME (e.g. tool adaptation). Finally and most importantly, the proposed frameworks have not been validated through the feasibility of metamodeling languages and tools.

To summarize, the research focus in the organizational context has been on tool-related aspects dealing with metaCASE selection, and on the identification of problems and requirements for tool customization. Accordingly, there is a paucity of research on tasks, organizational structures and mechanisms, and types of managerial coordination needed to carry out ME efforts. Researchers have so far focused mostly on proposing an organizational role for method engineers responsible for method management and redevelopment (e.g. Bubenko 1988, Kumar and Welke 1992).

\section{USE OF RESEARCH METHODS}

This section extends our survey by examining the use of research methods in ME research. In the following the use of research methods is discussed including references on published research. Table 1 summarizes the discussion. Some of the papers could not be classified into a single category: They focus on more than one context and apply multiple research methods. However, the aim of this survey is not to classify single papers but rather to find any overall bias in the use of research methods.

The majority of the surveys analyzed - although they have not focused specifically on ME rather on method use in general - falls into the organization context. However, these studies show only that organizations are developing methods in-house, rather than inspect how and why they are developed. In the technology context one survey was found (Karrer and Scacchi 1993)which examined the applications of meta-technology. Also, both of the field studies found (Smolander et al. 1990, Cronholm and Goldkuhl 1993) focus on tool and method 
adaptation, and thus investigated the capabilities of the customizable tools and organizational mechanism used during ME effort.

The role of the case studies is typically centered on describing the phenomena and their evolution in detail. In the language context Wijers (1991) conducted a case study using a knowledge acquisition approach to elicit method knowledge from three method engineers who had expertise for three different methods, and later using his modeling formalism to model each method. The finding shows the adequacy of the modeling formalism in coping with the three methods. We included also studies comparing ISD methods (cf. Song and Osterweil 1992, Song and Osterweil 1994) into case category, since they validate the framework through several method modeling cases. In the organization context, both case and action research studies have been carried out (cf. WoodHarper 1985, Slooten 1995, Tolvanen 1995). Many of the papers found describing ME projects, however, did not follow any case or action research method, and thus belong to the normative category.

Especially in the technology context, the dominant research approach has been applied research, to the degree that Nunamaker and Chen (1991) have developed a research approach, coined "software engineering research, which uses system building as a major research vehicle". Ever since the days of SEM (ISDOS 1985) tool research has focused on building environments (cf. reported environments: RAMATIC (Bergsten et al. 1989), MetaPlex (Chen et al. 1989), MetaEdit (Smolander et al. 1991), MetaView (Sorenson et al. 1988), and ConceptBase (Jarke et al. 1990)). Similarly in ME language development several papers seek to apply and extend existing theory or approaches from other closely related disciplines (databases, programming languages, software engineering, visual languages, and so on) to build and improve the capability of ME languages (Bronts et al. 1995, Liu 1995, Tolvanen et al. 1993a, Hong et al. 1993, Boloix et al. 1991a, Protsko et al. 1989, Saeki and Wenyin 1994).

Basic research has been densely concentrated in the language context (see table below). Although from the point of view of database modeling, some of the studies can be argued to be applied research (e.g. extensions to ER or NIAM), we believe that most of them (if not all) contribute to shape the theoretical basis of metamodeling. The numerous basic studies, on the other hand, reflect the fact that ME is still a young research area.

Normative writings can be found from each category. In the technology context some comparative research has emerged to categorize and compare features of available environments (e.g. see Marttiin et al. 1993) as well as to propose frameworks for designing environments (Goldkuhl and Cronholm 1993, Harmsen et al. 1994a). Several works in the language context make efforts either to generalize the requirements for ME languages, or to standardize the functionality of a ME language based on mathematics or conceptual framework (see table below). In the organization context some papers follow normative research since they propose a task of a method engineer (Kumar and Welke 1992), explains reasons for selecting customizable tools (Bubenko 1988), describe tool adaptation practices (Tagg 1990), or normative frameworks for ME (Slooten and Brinkkemper 1993).

Finally, and as important as the current use of research methods, there exist several research method and context combinations that have remained untouched (i.e. empty slots in the Table 1). First, there are fewer empirical studies than other research approaches; especially when compared to the use of applied research in tool development and basic research on language context. Second, the variety of research methods in the organization context is not being exploited to its full extent, since ME focused studies have used field studies and normative research. 


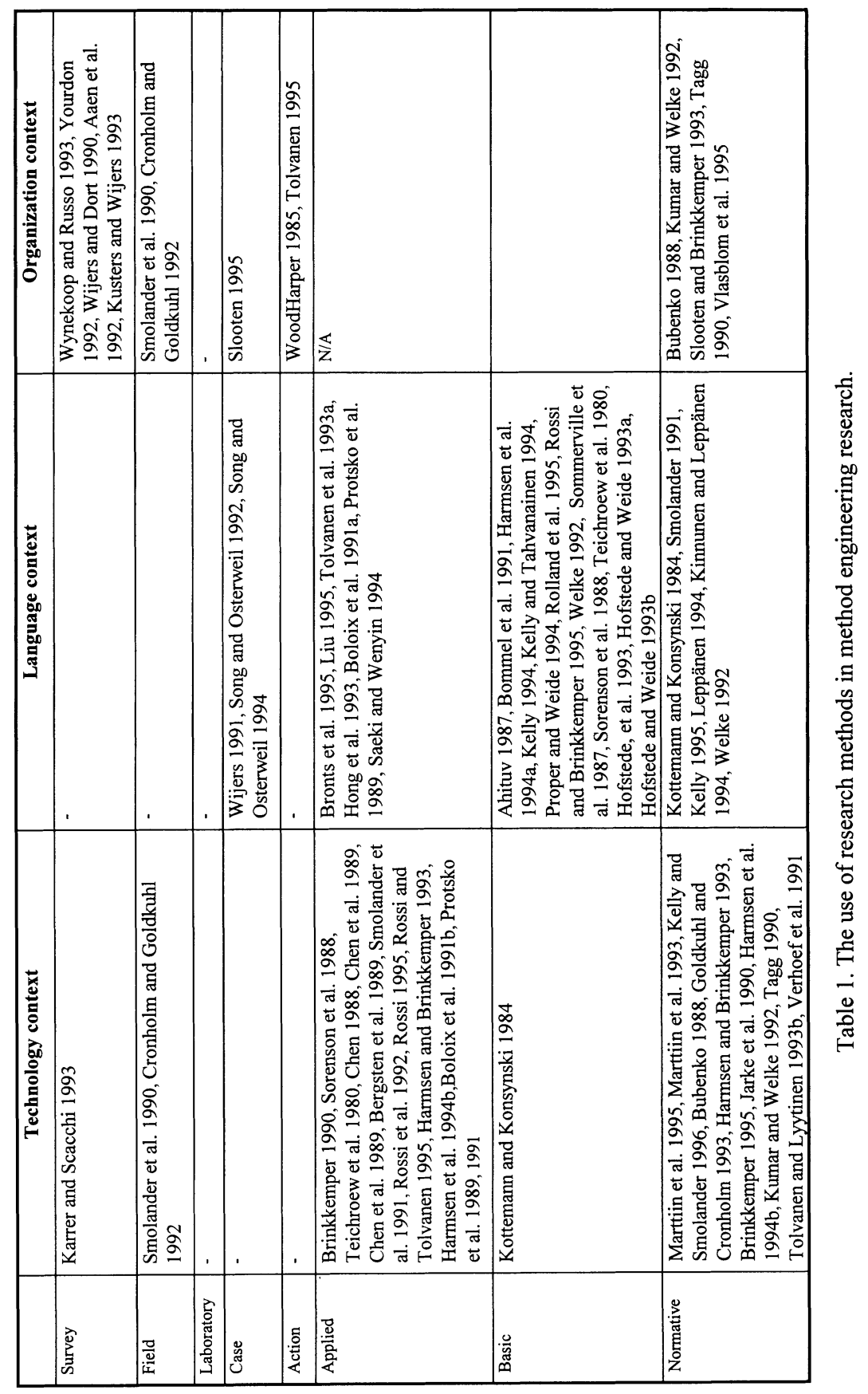




\section{DIRECTIONS FOR FUTURE RESEARCH}

The goal of any researcher is to generate "infallible" knowledge in his research field. In practice this means research collaboration, complementary research efforts, and use of a variety of research methods. For example, before building new metamodeling tools we need to have a good understanding of their current use and applicability. In the same vein, without research efforts towards developing new solutions and systems, there would be little opportunity for evaluative research (Nunamaker et al. 1991). In the following we shall contribute ideas for future ME research by proposing concrete research topics based on our survey: for each context and each research method some representative research questions will be raised (Table 2).

\subsection{Technical context}

Because earlier research has been mainly geared towards systems building, there is room for technical research that would verify the ideas put forth in the systems built. There is a huge amount of normative writing about the feasibility of different metamodeling approaches and environments, but no empirical (or even case based) research that could prove or refute these claims. Therefore, field research in particular should be encouraged, even though there are relatively few platforms that have so wide a user population that field research would be feasible. In addition to field studies based on several tools (such as Cronholm and Goldkuhl 1992) we also need case studies with detailed descriptions of tool use.

Because researchers have mainly built prototype systems, there have been few usability studies of the environments (e.g. Cronholm and Goldkuhl 1992). The usability of implemented CASE tools, as well as the usability of the method engineering tools, should be studied in practice.

\subsection{Language context}

For any modeling language, functionality and usability are always central issues, and ME languages are no exception. Future research on ME languages should thus concentrate on these aspects, either by extending existing research approaches or by creating new ones.

An obvious question concerning the functionality aspect is whether existing ME languages are sufficient to model all methods (according to the $100 \%$ principle of conceptual data modeling, see Griethuysen 1982). Although this question may never be answered with regard to the increasing emergence of "situational methods" we nevertheless need to answer it at some level. This necessitates the trial of ME languages using survey, field study, or case research. Another problem is weaknesses in existing ME languages to express constraints. Having evolved from general data modeling models or languages, existing ME languages are mainly capable of expressing specific semantic constraints imposed by the business data modeling domain. This constitutes a key deficiency in the functionality of ME languages, as the constraints in the method domain are quite different. Future work is needed on systematic study of ME-specific semantic constraints, and to develop a set of constraints for ME languages to cope with, ideally, an arbitrary set of constraints. 
Reuse strategies form another research issue which needs further investigation. The central problem is how to model and organize reusable method fragments, and how to develop sufficient and effective means for retrieving promising reusable objects. Another important research question is ME languages' support for systematic and unbiased method comparison or characterization. Though the outcomes of the research in this problem area are encouraging, they address only a partial characterization of methods. A natural problem arises over whether it is feasible to standardize the quality of methods. Insofar as it is possible, such a standard could no doubt improve the ME process by allowing at least partial automation of the evaluation of a method supported by a ME language.

One (implicit) assumption for the shift from a textual ME language to a visual one lies in the belief of the improved user friendliness. No studies in the ME area have been found to support it, beyond a short comment in (Goldkuhl and Cronholm 1993). This necessitates empirical research, for example laboratory experiments, to evaluate not only this belief, but also investigate user preferences for different visual representational paradigms. The implementation of visual paradigms should also be improved to address the wide spectrum of the functionality of the ME languages support. This includes, for instance, the investigation of the role of visual languages for the querying and retrieval of reusable method fragments.

\subsection{Organization context}

As stated above there is a paucity of ME research in the organization context. Although several surveys of method use have been performed there is still a need for new ones. One reason for this is that existing studies (e.g. Wijers and Dort 1990, Aaen et al. 1992, Yourdon 1992, Russo et al. 1995) obtain different results: for example the popularity of method adaptation and thus in-house method development differs in the studies between $36 \%$ and $65 \%$. Accordingly, it seems that there is no consensus on what method adaptation means (e.g. modification of phases on a general level or modification of the details of a method's concepts and notations). Similarly we do not know whether stakeholders are more satisfied with inhouse methods than with methods taken as given.

The difficulty in survey studies is in the collection of detailed data. Field studies and case studies are more suitable for investigating in detail questions such as why in-house methods are developed, do in-house methods work and how ME efforts are organized. For the last question we can already find several alternatives for ME projects on the organizational level: ME can be done for a whole organization (cf. SDM by Turner et al.1988), for a single development project (cf. Vlasblom et al. 1995), or for a developed product (cf. Aalto 1993). Similarly the stakeholder's roles and tasks during ME efforts need to be studied: current research merely proposes a role of 'method engineer', although in-house method development also has other stakeholders. Field studies (Smolander et al. 1990, Cronholm and Goldkuhl 1992) have noted only a few of these stakeholders, and their roles have not been studied.

Finally, action research may be needed for examining what has caused success or failure in in-house method development, what decisions are made during ME, how frequently methods are changed, and how method evolution is controlled. These questions typically presuppose longitudinal research efforts as well as close interaction in method use and method development situations. 


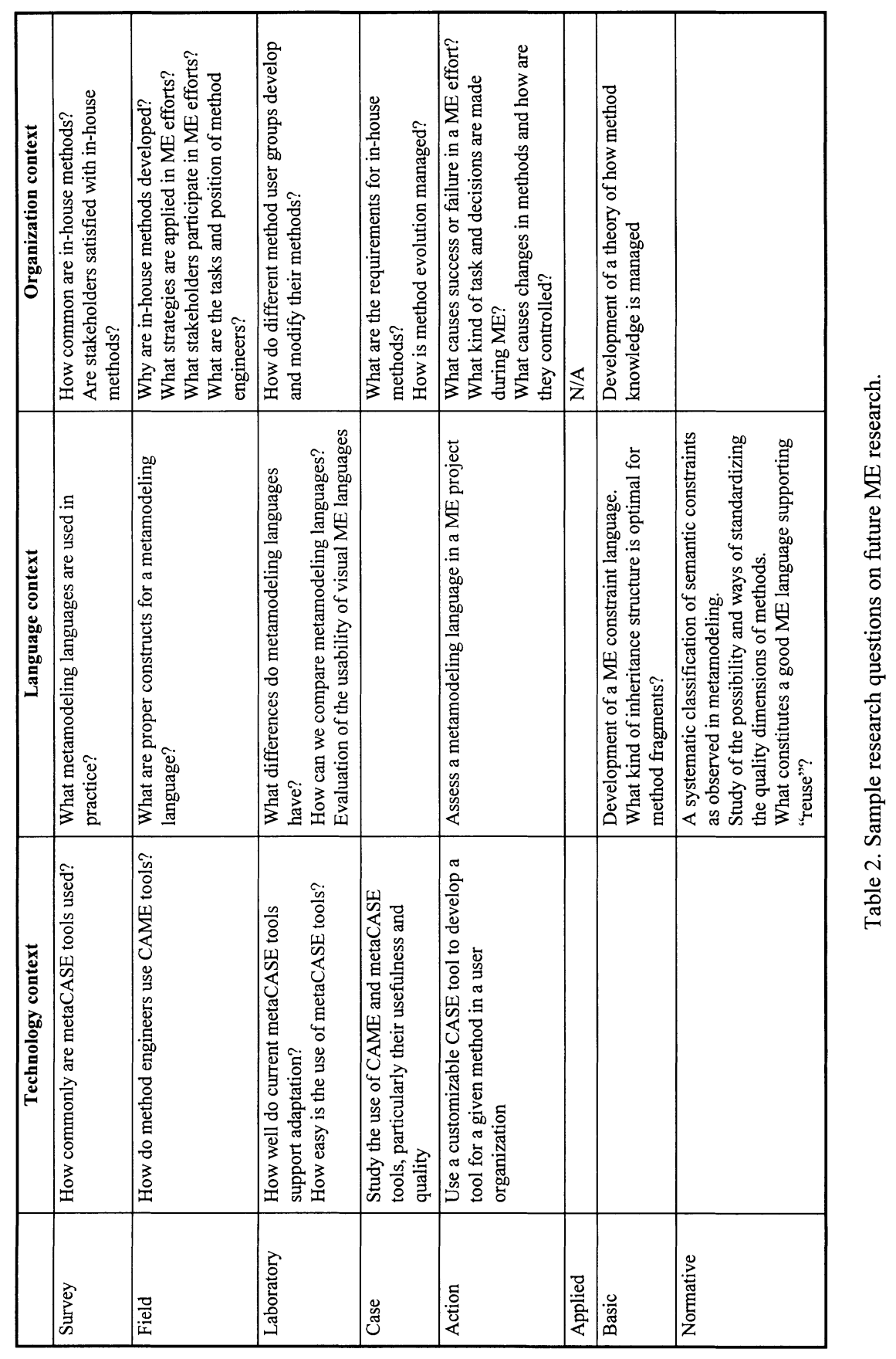




\section{SUMMARY}

In this paper we conducted a survey of method engineering research approaches. Over 80 papers, found from journals and conference publications, were classified using Lyytinen's (1987) three contexts: technology, language and organization. A second dimension of classification was the chosen research paradigm(s) (i.e. survey, field study, laboratory experiment, case study, action research, applied, basic or normative) according to the framework of Wynekoop and Conger (1991).

Some interesting observations can be made from the amount of literature in each context and research approach. A pattern of distribution similar to that of Wynekoop and Conger can be found: most papers appeared in the applied, basic and normative categories. In the same vein the technical and language contexts predominate in the organizational context. Although a new field is often dominated by applied or constructive research, the now numerous available environments and languages call for evaluative research approaches. The lack of empirical studies can be partially explained by the relatively short time that method engineering tools have been used in ISD organizations.

For the field of method engineering to progress, we must widen the range of research methods we use. Many more empirical studies are needed to investigate the applicability of the tools and languages developed. Too often tools and languages are developed without empirical justification or evaluation outside the research group. The absence of studies in the organizational context must also be addressed, since organizational issues are essential for ME to achieve its purpose. Again, empirical studies are needed for obtaining a comprehensive view of ME practices. Alongside these empirical studies, new ideas and approaches are needed for organizational issues such as method management, method evolution, and use of method users' requirements to guide ME efforts.

Method engineering is an endeavor that takes place over time, extending over various method versions, ISD projects, and even tools. Research in ME should therefore also be directed towards longitudinal studies: research to date has mostly dealt with "snapshots" of ME. Finally, ME research is only a part of the research activities in IS, and it should therefore be tied in with research in other related disciplines in the field, such as IS development, computer-aided environments, software process improvement and requirements engineering.

\section{ACKNOWLEGEMENTS}

The authors would like to thank Steven Kelly for proofreading and valuable additions to the paper, and the anonymous referees for their constructive comments.

\section{REFERENCES}

Aaen, Ivan, Aila Siltanen, Carsten Sørensen and Veli-Pekka Tahvanainen (1992), "A Tale of Two Countries: CASE Experiences and Expectations," in The Impact of Computer Supported Technologies on Information Systems Development, K. E. Kendall, K. Lyytinen and J. I. DeGross (Ed.), North-Holland, Amsterdam, pp. 61-93. 
Aalto, J.-M. (1993), "Experiences on Applying OMT to Large Scale Systems," in Proceedings of the Seminar on Conceptual Modelling and Object-Oriented Programming, A. Lehtola and J. Jokiniemi (Ed.), Finnish Artificial Intelligence Society, pp. 39-47 .

Ahituv, Niv (1987), "A metamodel of information flow: a tool to support information systems theory," Communications of the ACM 30(9), pp.781-791.

Benbasat, I., D. Goldstein and M. Mead (1987), "The Case Research Strategy in Studies of Information Systems," MIS Quartely (September), pp.369-386.

Bergsten, Per, Janis Bubenko jr., Roland Dahl, Mats Gustafsson and Lars-Åke Johansson (1989), "RAMATIC - A CASE Shell for Implementation of Specific CASE Tools," Tempora T6.1 Report, first draft, SISU, Gothenburg.

Boloix, G., P. G. Sorenson and J. P. Tremblay (1991), "On Transformations Using A Metasystem Approach To Software Development," TR 91-19, The University of Alberta, Edmonton, Alberta, Canada (November).

Boloix, G., P. G. Sorenson and J. P. Tremblay (1991), "Software Metrics using a Metasystem Approach to Software Specification," Technical Report, The University of Alberta, Canada.

Bommel, P. van, A. H. M. ter Hofstede and Th.P. van der Weide (1991), "Semantics and verification of object-role models," Information Systems 16(5) pp.471-495.

Brinkkemper, Sjaak (1990), “Formalisation of Information Systems Modelling," Ph.D. Thesis, Univ. of Nijmegen, Thesis Publishers, Amsterdam.

Brinkkemper, Sjaak (1995), "Method engineering: engineering of information systems development methods and tools," Information \& Software Technology 37(11) pp.1-6.

Bronts, G.H.W.M., S.J. Brouwer, C.L.J. Martens and H.A. Proper (1995), “A unifying object role modelling theory," Information Systems 20(3) pp.213-235.

Bubenko, J. A. (1988), "Selecting a Strategy for Computer-Aided Software Engineering (CASE)," 59, SYSLAB, University of Stockholm, Sweden.

Chen, Minder (1988), "The Integration of Organization and Information Systems Modeling: A Metasystem Approach to the Generation of Group Decision Support Systems and Compute-aided Software Engineering," PhD Thesis, University of Arizona, Tuscon, USA.

Chen, M., J. F. Nunamaker Jr. and E. S. Weber (1989), "The Use of Integrated Organization and Information Systems Models in Building and Delivering Business Application Systems," IEEE Transactions on Knowledge and Data Engineering 1(3), pp.406-409.

Chen, Minder, Jr. Jay F. Nunamaker (1989), "METAPLEX: An integrated environment for organization and information systems development," pp. 141--151 in Proceedings of the Tenth International Conference on Information Systems, December 4--6, 1989, Boston, Massachusetts, J. I. DeGross, J. C. Henderson, and B. R. Konsynski (Ed.), ACM Press.

Chen, M., J. F. Nunamaker Jr. and G. Mason (1991), "The Architecture And Design Of A Collaborative Environment For Systems Definition," Database (Winter/Spring) pp. 22-28.

Cronholm, S., G. Goldkuhl (1992), "Meanings and motives of method customisation in CASE environments - observations and categorizations from an empirical study," Proceeding of the fifth workshop on the next generation of CASE tools, University of Twente, Twente.

Dowson, M. (1987), "Iteration in the software process," pp. 36-39 in Proc of 9th Int. Conf. Software Engineering, San Francisco. 
Galliers, R. D. (1991), "Choosing Appropriate Information Systems Research Approaches: A Revised Taxonomy," pp. 327-348 in Information Systems Research, H.-E. Nissen, H. K. Klein and R. Hircheim (Ed.), North-Holland, Amsterdam.

Gigch, J. van (1991), "Systems design and modeling and metamodeling," Plenum Press, New York.

Goldkuhl, Göran, Stefan Cronholm (1993), "Customizable CASE Environments: A Framework for Design and Evaluation," Accepted to COPE IT '93. LiTH-IDA-R-93-42, Linköping University, Sweden.

Griethuysen, J.J. van (1982), "Concepts and terminology for the conceptual schema and the information base," ISO/TC97/SC5-N695, ISO.

Grundy, J. C., J. R. Venable (1995), "Providing Integrated Support for Multiple Development Notations," pp. 255-268 in Proceedings of the 7th International Conference on Advanced Information Systems Engineering, CAISE'95, J. Iivari, K. Lyytinen and M. Rossi (Ed.), Springer-Verlag.

Harmsen, F., S. Brinkkemper (1993), "Computer Aided Method Engineering based on existing Meta-CASE technology," pp. 125-140 in Proceedings of the Fourth Workshop on The Next Generation of CASE Tools, Sjaak Brinkkemper, Frank Harmsen (Ed.) No. 93-32, Univ. of Twente, Enschede, the Netherlands.

Harmsen, F., S. Brinkkemper and H. Oei (1994), "A language and tool for the engineering of situational methods for information systems development," pp. 206--214 in Proceedings of the Fourth International Conference on Information Systems Development, J. Zupansis and S. Wrycza (Ed.), Moderna Organizacija, Kranj, Slovenia.

Harmsen, Frank, Sjaak Brinkkemper and Han Oei (1994), "Situational Method Engineering for Information System Project Approaches," pp. 169--194 in Methods and Associated Tools for the Information Systems Life Cycle (A-55), A. A. Verrijn-Stuart and T. W. Olle (Ed.), Elsevier Science B.V. (North-Holland).

Heym, M., H. Österle (1992), "A Semantic Data Model for Methodology Engineering," in Proceedings of the Fifth CASE '92 Workshop, Montreal, G. Forte and N. Madhavji (Ed.), IEEE Computer Society Press, Los Alamitos.

Heym, M., H. Österle (1992), "A Reference Model of Information Systems Development," pp. 215--240 in The Impact of Computer Supported Technologies on Information Systems Development, K. E. Kendall, K. Lyytinen, J. L. DeGross (Ed.), North-Holland, Amsterdam.

Heym, M., H. Österle (1993), "Computer-aided methodology engineering," INFORMATION AND SOFTWARE TECHNOLOGY 35(6/7) pp.345--354.

Hidding, Gezinus J., Gwendolyn M. Freund and Johan K. Joseph (1993), "Modeling Large Processes with Task Packages," Workshop on Modeling in the Large, AAAI Conference, Washington, D.C..

Hofstede, A. H. M. ter, T. F. Verhoef, E. R. Nieuwland and G. M. Wijers (1992), "Integrated Specification of Method and Graphic Knowledge," Proceedings of the Fourth International Conference on Software Engineering and Knowledge Engineering pp.307-316.

Hofstede, A. H. M. ter, T. F. Verhoef, E. R. Nieuwland and G. M. Wijers (1992), "Specification of Graphic Conventions in Methods," pp. 185--215 in Proceedings of 3rd Workshop on Next Generation of CASE Tools, B. Theodoulidis and A. Sutcliffe (Ed.), UMIST, Manchester, UK.

Hofstede, A. H. M. ter (1993), "Information Modelling in Data Intensive Domains," $\mathrm{PhD}$ Thesis, University of Nijmegen, Nijmegen. 
Hofstede, A. H. M. ter, Th. P. van der Weide (1993), “Expressiveness in data modeling," Data \& Knowledge Engineering (10) pp.65-100.

Hofstede, A. H. M. ter, Th. P. van der Weide (1993), "Formalisation of techniques: chopping down the methodology jungle," Information \& Software Technology 34(1) pp.57-65.

Hofstede, A. H. M. ter, E. R. Nieuwland (1993), "Task structure semantics through process algebra," Software Engineering Journal (8) pp.14-20.

Hofstede, A. H. M. ter, H. A. Proper and Th. P. van der Weide (1993), "Formal definition of of a conceptual language for the description and manipulation of information models," Information Systems $18 \mathrm{pp}$.489-523.

Hong, S., G. van den Goor and S. Brinkkemper (1993), "A Comparison of Six ObjectOriented Analysis and Design Methods," in Proceedings of the 26th Hawaiian Conference on Systems Sciences, IEEE Computer Science Press.

Hull, Richard, Roger King (1987), "Semantic Database Modeling Survey, Applications, and Research Issues," ACM COMPUTING SURVEYS 19(3) pp.201--260.

ISDOS, (1985), "System Encyclopedia Manager, Language Definition Manager: User Manual (SEM/LDM)," Version 1.4 (June).

Jarke, Matthias, Manfred Jeusfeld and Thomas Rose (1990), "A Software Process Data Model For Knowledge Engineering In Information Systems," Information Systems 15(1) pp.85-116.

Jarke, M., J. Mylopoulos, J. Schmidt and Y. Vassiliou (1991), "DAIDA: An Environment for Evolving Information Systems," RWTH Aachen, Aachen.

Jenkins, A. M. (1985), "Research Methodologies in MIS Research," pp. 103-118 in Research Methods in Information Systems, E. Mumford, R. Hirschheim, G. Fitzgerald and A.T. Wood-Harper (Ed.), Elsevier Science Publishers.

Karrer, A., W. Scacchi (1993), "Meta-Environments for software production," International Journal of Software Engineering and Data Engineering 3(1) pp.139-162.

Kelly, Steven (1994), "A Matrix Editor for a MetaCASE Environment," Information and Software Technology 36(6) pp.361--371.

Kelly, Steven, Veli-Pekka Tahvanainen (1994), "Support for Incremental Method Engineering and MetaCASE," in Proceedings of the 5th Workshop on the Next Generation of CASE Tools, B. Theodoulidis (Ed.) No. Memoranda Informatica 94-25, Universiteit Twente, Enschede, the Netherlands.

Kelly, Steven (1995), "What's in a Relationship: on distinguishing property holding and object binding," in Proceedings of 3rd International Conference on Information Systems Concepts, ISCO 3, W. Hesse and E. Falkenberg (Ed.), University of Marburg, Lahn, Germany.

Kelly, Steven, Kari Smolander (1996), "Evolution and Issues in MetaCASE," Information and Software Technology (to appear) .

Kinnunen, Kimmo, Mauri Leppänen (1994), "O/A Matrix and a Technique for Methodology Engineering," in Proceedings of the Fourth International Conference on Information Systems Development, J. Zupansis and S. Wrycza (Ed.), Moderna Organizacija, Kranj, Slovenia.

Kottemann, J. E., B. R. Konsynski (1984), "Dynamic Metasystems for Information Systems Development," pp. 187--204 in Proceedings of the Fifth International Conference on Information Systems. 
Kumar, Kuldeep, Richard J. Welke (1992), "Methodology Engineering: A Proposal for Situation Specific Methodology Construction," pp. 257--269 in Challenges and Strategies for Research in Systems Development, Kottermann W. W. and Senn J. A. (Ed.), John Wiley \& Sons, Washington.

Kusters, R. J., G. M. Wijers (1993), "On the Practical Use of CASE Tools: Results of a survey," pp. 2--10 in Proceedings of the 6th International Workshop on Computer-Aided Software Engineering, CASE93, Hing-Yan Lee, Thomas F. Reid and Stan Jarzabek (Ed.), IEEE Computer Society.

Leppänen, Mauri (1994), "Metamodelling: Concept, Benefits and Pitfalls," pp. 126--137 in Proceedings of the Fourth International Conference on Information Systems Development, J. Zupansis and S. Wrycza (Ed.), Moderna Organizacija, Kranj, Slovenia.

Liu, H. (1995), "A Visual Interface for Querying a CASE Repository," in Proc. of the Eleventh IEEE Symposium on Visual Languages (VL'95), Darmstadt.

Lyytinen, Kalle (1987), "A Taxonomic Perspective of Information Systems Development: Theoretical Constructs and Recommendations," pp. 3--41 in Critical Issues in Information Systems Research, R. J. Boland Jr. and R. A. Hirschheim (Ed.), John Wiley \& Sons Ltd..

Lyytinen, Kalle, Kari Smolander and Veli-Pekka Tahvanainen (1989), "Modelling CASE Environments in Systems Development," in Proceedings of the first Nordic Conference on Advanced Systems, SISU, Stockholm.

Marttiin, Pentti, Matti Rossi, Veli-Pekka Tahvanainen and Kalle Lyytinen (1993), " $A$ Comparative review of CASE shells: A preliminary framework and research outcomes," Information \& Management 25 pp.11-31.

Marttiin, P. (1994), "Towards Flexible Process Support with a CASE shell," pp. 14--27 in Advanced Information Systems Engineering, Proceedings of the Third International Conference CAiSE'94, Utrecht, The Netherlands, June 1994, G. Wijers, S. Brinkkemper and T. Wasserman (Ed.), Springer-Verlag, Berlin.

Marttiin, Pentti, Kalle Lyytinen, Matti Rossi, Veli-Pekka Tahvanainen and Juha-Pekka Tolvanen (1995), "Modeling requirements for future CASE: issues and implementation considerations," Information Resources Management Journal 8(1) pp.15--25.

Norman, Ronald J., Minder Chen (1992), "Working Together to Integrate CASE," IEEE Software (March) pp.12--17.

Nunamaker, Jay F., Minder Chen and Titus D. M. Purdin (1991), "Systems Development in Information Systems Research," Management Information Systems 7(3) pp.89--106.

Oei, J. L. H., L. J. G. T. van Hemmen, E. D. Falkenberg and S. Brinkkemper (1992), "The Meta Model Hierarchy: A Framework for Information for Information Systems Concepts and Techniques," University of Nijmegen, Nijmegen.

Oei, J. L. H., E. D. Falkenberg (1994), "Harmonisation of information systems modelling and specification techniques," pp. 151--168 in Methods and Associated Tools for the Information Systems Life Cycle, A. A. Verrijn-Stuart and T. W. Olle (Ed.) No. A-55, Elsevier Science publishers.

Oei, J.L.H. (1995), "A meta model transformation approach towards harmonisation in information system modelling," pp. 106-127 in Information System Concepts - Towards a consolidation of views, E. D. Falkenberg, W. Hesse and A. Olivé (Ed.), Chapman \& Hall, London.

Olle, T.W., H. Sol and A. Verrijn-Stuart (1983), "Informations systems design methodologies: A feature analysis," North-Holland, Amsterdam. 
Olle, T. W. (1992), "A Comparative Review of the ISO IRDS, the IBM Repository and the ECMA PCTE as a Vehicle for CASE Tools," pp. 147--165 in CASE: Current Practice, Future Prospects, Kathy Spurr and Paul Layzell (Ed.), Wiley.

Proper, H. A., Th. P. van der Weide (1994), "EVORM: A conceptual modelling technique for evolving application domains," Data \& Knowledge Engineering 10(12) pp.313-359.

Protsko, L. B., P. G. Sorenson and J. P. Tremblay (1989), "Mondrian: system for automatic generation of dataflow diagrams," Information and Software Technology 31(9) pp.456471.

Protsko, L. B., P. G. Sorenson, J. P. Tremblay and D. A. Schaefer (1991), "Towards the Automatic Generation of Software Diagrams," IEEE TRANSACTIONS ON SOFTWARE ENGINEERING 17(1).

Rolland, C., C. Cauvet (1992), "Trends and Perspectives in Conceptual Modeling," pp. 27--48 in Conceptual Modelling, Databases and CASE: An Integrated View of Information Systems Development, P. Loucopoulos and R. Zicari (Ed.), Wiley, New York.

Rolland, C., C. Souveyet and M. Moreno (1995), "An approach for defining ways-ofworking," Information Systems 20(4) pp.337-359.

Rossi, M., M. Gustafsson, K. Smolander, L.-Å. Johansson and K. Lyytinen (1992), "Metamodeling editor as a front end tool for a case-shell," pp. 547--567 in Advanced Information Systems Engineering, P. Loucopoulos (Ed.), Springer Verlag, Berlin, Germany.

Rossi, M., J-P. Tolvanen (1995), "Using Reusable Frameworks in Development of a Method Support Envionment," in Proceedings of The WITS 1995, Amsterdam, The Netherlands, M. Jarke, S. Ram (Ed.), pp. 240-249.

Rossi, M., S. Brinkkemper (1995), "Metrics in Method Engineering," pp. 200-216 in Advanced Information Systems Engineering, Proceedings of the 7th International Conference CAiSE'95, J. Iivari, K. Lyytinen and M. Rossi (Ed.) No. 932, Springer-Verlag, Berlin.

Rossi, M. (1995), "The MetaEdit CAME environment," Proceedings of the MetaCase 95, University of Sunderland press, Sunderland.

Russo, Nancy L., Judy L. Wynekoop and Diane B. Walz (1995), "The Use and Adaptation of System Development Methodologies," in Proceedings of the 1995 International Resources Management Association Conference, Atlanta.

Saeki, Motoshi, Kuo Wenyin (1994), "Specifying Software Specification \& Design Methods," pp. 353--366 in CAiSE '94 Proceedings, Gerard Wijers, Sjaak Brinkkemper and Tony Wasserman (Ed.) Vol. Lecture Notes in Computer Science 811, Springer-Verlag, Berlin.

Slooten, Kees van, Sjaak Brinkkemper (1993), "A Method Engineering Approach to Information Systems Development," in Procs. of the IFIP WG 8.1 Working Conference on the Information Systems Development Process, N. Prakash, C. Rolland, B. Pernici (Ed.), North-Holland, Amsterdam.

Slooten, Kees van (1995), "Situated Methods for Systems Development," PhD Thesis, University of Twente, Twente.

Smolander, Kari, Veli-Pekka Tahvanainen and Kalle Lyytinen (1990), "How to Combine Tools and Methods in Practice: a field study," pp. 195--214 in Advanced Information Systems Engineering, proceedings of the Second Nordic, B. Steinholz, A. Sölvberg, L. Bergman (eds) (Ed.), Springer-Verlag, Berlin. 
Smolander, Kari, Kalle Lyytinen, Veli-Pekka Tahvanainen and Pentti Marttiin (1991), "MetaEdit --- A Flexible Graphical Environment for Methodology Modelling," pp. 168-193 in Advanced Information Systems Engineering, Proceedings of the Third International Conference CAiSE'91, Trondheim, Norway, May 1991, R. Andersen, J. A. Bubenko jr. and A. Solvberg (Ed.), Springer-Verlag, Berlin.

Smolander, Kari (1991), "OPRR: A Model for Modelling Systems Development Methods," in Next Generation CASE Tools, K. Lyytinen and V.-P. Tahvanainen (Ed.), IOS Press, Amsterdam, the Netherlands.

Sommerville, I., R. Welland and S. Beer (1987), "Describing software design methodologies," The Computer Journal 30(2) pp.128-133.

Song, X., L. Osterweil (1992), "Towards Objective and Systematic Comparisons of Software Design Methodologies," IEEE Software 18(5) pp.43--53.

Song, X., L. J. Osterweil (1994), "Experience with an Approach to Comparing Software Design Methodologies," IEEE Transactions on Software Engineering 20(5) pp.364--384.

Sorenson, Paul G., Jean-Paul Tremblay and Andrew J. McAllister (1988), "The Metaview System for Many Specification Environments," IEEE SOFTWARE (March) pp.30--38.

Tagg, B. S. (1990), "Implementing Tool Support for Box Structures," IBM Systems Journal 29(1).

Teichroew, D., P. Macasovic, III E. A. Hershey and Y. Yamamoto (1980), "Application of the entity-relationship approach to information processing systems modeling," pp. 15--38 in Entity-Relationship Approach to Systems Analysis and Design, P. P. Chen (Ed.), NorthHolland.

Tolvanen, J.-P., P. Marttiin and K. Smolander (1993), "An integrated model for information systems modeling," pp. 470-479 in Proceedings of 26th HICSS, J. Nunamaker and H. Sprague (Ed.) Vol. 3, IEEE Computer Society Press, Los Alamitos.

Tolvanen, J.-P., K. Lyytinen (1993), "Flexible method adaptation in CASE environments The metamodeling approach," Scandinavian Journal of Information Systems 5(1) pp.5177.

Tolvanen, J.-P. (1995), "Incremental Method Development for Business Modelling: An Action Research Case Study," pp. 79-98 in Proceedings of the 6th Workshop on the Next Generation of CASE Tools, NGCT'95, G. Grosz (Ed.), University of Paris 1, Paris.

Turner, W. S., R. P. Langerhorst, G. F. Hice, H. B. Eilers and A. A. Uijttenbroek (1988), "SDM: system development methodology," North-Holland.

Verhoef, T. F., A. H. M. ter Hofstede and G. M. Wijers (1991), "Structuring modelling knowledge for CASE shells," pp. 502-524 in Advanced Information Systems Engineering, Proceedings of the Third International Conference CAiSE'91, R. Andersen, J. A. Bubenko and A. Solvberg (Ed.), Springer-Verlag.

Vlasblom, G., D. Rijsenbrij and M. Glastra (1995), "Flexibilization of the methodology of system development," Information \& Software Technology 37(11) pp.595-607.

Welke, R. J. (1988), "Metabase: A Platform for the Next Generation of Meta Systems Products," in Proceedings of the Ninth Annual Conference on Applications of ComputerAided Software Engineering Tools, May 23--27, 1988, Meta Systems Ltd., Ann Arbor, MI.

Welke, R. J. (1992), "The CASE Repository: More than another database application," in Challenges and Strategies for Research in Systems Development, William W. Cotterman and James A. Senn (Eds.) (Ed.), Wiley, Chichester UK. 
Wijers, G. M., H. E. van Dort (1990), "Experiences with the use of CASE-tools in the Netherlands," Advanced Information Systems Engineering pp.5--20.

Wijers, G. M. (1991), "Modelling Support in Information Systems Development," Ph.D. Thesis, Delft University of Technology, Thesis Publishers, Amsterdam.

Wijers, G. M., A. H. M. ter Hofstede and N. E. van Oosterom (1992), "Representation of Information Modelling Knowledge," in Next Generation CASE Tools, K. Lyytinen and V.P. Tahvanainen (Ed.), IOS Press, Amsterdam, The Netherlands.

Wood-Harper, T. (1985), "Research Methods in Information Systems: Using Action Research," pp. 169-191 in Research Methods in Information Systems, E. Mumford, R. Hirschheim, G. Fitzgerald and A.T. Wood-Harper (Ed.), Elsevier Science Publishers.

Wynekoop, J. L., S. A. Conger (1991), "A review of computer aided software engineering research methods," Information Systems Research, IFIP.

Wynekoop, J. D., N. L. Russo (1993), "System development methodologies: unanswered questions and the research-practice gap," pp. 181--190 in Proceedings of the 14th ICIS, J. I. DeGross, R. P. Bostrom and D. Robey (Ed.), ACM, Orlando, USA.

Yourdon, E. (1992), "The Decline and Fall of the American Programmer,," Prentice-Hall, Englewood Cliffs, NJ.

\section{BIOGRAPHY}

The authors work as researchers in the MetaPHOR project at the Department of Computer Science and Information Systems in the University of Jyväskylä. Juha-Pekka Tolvanen received his Master's degree in 1992 and licentiate degree in 1994. His licentiate thesis and dissertation research focus on method engineering and especially on its organizational and methodical aspects. His other research interests include CASE tools, business modeling and business process re-engineering. Matti Rossi received his Master's degree in 1994 and completed his licentiate thesis in 1994. His research interests include database management, object-oriented data representation, metamodelling, transformations in metamodelling, and the applications of these to software engineering. Hui Liu received his Master's degree in Beijing and completed his licentiate thesis in 1996 in Jyväskylä. His research interests include metamodelling languages and query systems, in particular visual query languages in metaCASE environments. 